\title{
The work of bus drivers and their contribution to excellence in public transportation
}

\author{
Claudio Marcelo Brunoro ${ }^{\text {a* }}$, Laerte ldal Sznelwara, Ivan Bolis ${ }^{\mathrm{a}}$, Julia Abrahao \\ a*Universidade de São Paulo, São Paulo, SP, Brasil, cbrunoro@uol.com.br
}

\begin{abstract}
The article is the result of a survey aimed at analyzing the work of bus drivers for a collective urban transportation company that is considered a benchmark. The research sought to understand how the company could maintain a policy capable of reconciling the quality of public transportation with working conditions that are compatible with the professional development, comfort and health of the workers. The ergonomic work analysis methodology was adopted as a guide. The results show that one of the pillars of excellence achieved by this company is the quality of the work performed by their drivers, which is guided by the organizational values that permeate the organization. The driver plays a role in regulating the system by serving the population and providing mobility. Their activity is controlled by a series of interdependent variables, such as the demands for conducting the vehicle and the relationship with others.
\end{abstract}

Keywords

Activity theory. Bus drivers. Ergonomics. Public transportation. Work design and organization.

\section{Introduction}

Urban mobility is a central issue to modern society and there are numerous challenges involved in providing conditions for people to move comfortably, safely and to reach the desired destination.

The activities of transport workers, such as bus drivers, the main objective of which is to ensure mobility for the population, involve constant challenges with significant impact on their health. Ensuring mobility in conditions that are not always conducive requires diligence, constant effort and mobilization of skills in order to achieve the outlined goals. However, little is known about the actual work performed by such workers, especially when one considers the transport system as a service production network, which includes numerous linked activities that feed each other back. These services, as well as any other public services need to be reliable, once they are essential to ensuring citizenship rights and also because they are fundamental pillars for the economy. Thus, system reliability is crucial to ensure essential mobility for economic functioning. Failures generate significant nuisance for the population, favoring accident scenarios that could reach large proportions.

Private companies under public licenses modulated by long-term contracts largely operate public transport. Public bodies perform a regulation role, ensuring that the service hired will be provided, and usually perform the system planning and control. The different workers operating in this system develop their work influenced by factors that are often not clear to them. For example, the role of promoting the regulation of the transport system (operational level) and concurrently ensuring citizenship rights to the user providing mobility in the public space is central to the work of the bus drivers, since it is not clearly described in their contract.

Concerning transportation, decisions occur at levels that exceed the exclusive influencing power of the company. As a result of historical issues and political decisions, both requirements with respect to the service being provided by companies and conditions for financing operations define the scope of the company's investment. Among these decisions, 
we emphasize the maintenance of good working conditions, quality of the equipment, maintenance and hiring policies, as well as flexibility to cope with the various events that could change the course of operations in relation to what was foreseen.

The company's governance is limited by a number of contractual issues and reality, including the relationship with passengers and their needs, the city's characteristics, and the incorporation of different types of transport technologies, including vehicles. As could be expected, the process is conditioned by the relationship between costs and revenues that define the margins of maneuver of the different actors taking part in the system. The search and maintenance of excellence result from an organizational congruence that involves all the levels of the company and, more directly, operation and maintenance.

The prospect of excellence in public transportation is based on a series of challenges concerning operation and their direct support, including drivers, whose work is the focus of this paper, in view of the importance of their role in operating the criterion that mediates excellence. Under this perspective, there is the work of those who are in direct contact with passengers: the duo driver/collector (the crew). This organizational congruence is supported by the favorable conditions provided in the work context aimed at developing the skills needed to build service excellence and the work of this duo, especially the driver's, is ultimately responsible for the visibility of transportation excellence. In this case, transportation excellence means ensuring excellence in people's mobility, especially to those with disabilities and different needs and desires.

Under this perspective, we based our initial hypothesis: building and the constant pursuit of excellence depends on an organizational congruence able to integrate different aspects such as the work done by its employees, the inclusion of mobility quality as a citizenship factor, and technological development as a comfort element for drivers and passengers. Not only these aspects interrelated but there are also other key issues related to government costs and strategies regarding transportation and mobility.

Throughout its history, one of excellence pillars is the quality of drivers' work guided by the organizational values that permeate the organization. In this study, we rely on two assumptions: building and pursuing service excellence as a constant challenge that depends on factors that are internal and external to the organization, once the job of a bus driver is not restricted to driving a vehicle and cannot be considered a mere dislocation of passive objects from one place to another.

The company studied is a public institution, which gives unique characteristics regarding the public transport system the company operates, since all the others are private. It operates in a large city in Brazil (nearly $500 \mathrm{~km}^{2}$ and 1.5 million inhabitants) and it is not possible to provide more details (non-disclosure agreement). The country has experienced a political-socioeconomic situation aimed at advocating the rights of the population to better quality and excellence in public services. As to the public transport system, the mandatory requirements based on service improvement, not only related to the fleet average age, but also to the quality of the fleet, mainly for the user, are still under discussion and minimum desirable conditions have not yet been defined in Brazil, despite being already ensured and even overcome in many countries. In this sense, the orientation of these conditions due to the existence of a (public) company distinguished for its level of excellence, regardless of the requirements currently regulated, may possibly provide subsidies to better define new concession contract requirements.

\section{Methodology}

Better understanding the job and seek for its improvement, beginning with the analysis of the conditions and constraints to which workers are exposed, goes far beyond the simple definition of previously prescribed procedures and routines established for the job. In this sense, events and incidents permeate the workers' activity, especially because the company's operations take place in the city public space. All the work activities take place in the dialectical tension between what was predicted and therefore prescribed as a task, and what is effectively developed over the operations. The work activity is built considering the operation needs and objectives, given the conditions, the events and the ever changing conditions of each worker. It is essential to take into consideration the diversity of situations and of the individuals who work, as well as the variability inherent to the production process and to the individuals in order to build a management process that aims at excellence. Still, concerning public services, there are significant challenges associated with meeting targets including citizens' desires and needs.

In ergonomics, one of the purposes of an action is to illustrate the actual work, avoiding generalizations using average values, highlighting work aspects that are often unknown and therefore invisible and unrecognized. However, the activity 
does not occur isolated from the context, it is built by workers using the tasks they should perform as a reference. The tasks are part of the organization universe, of the company's definition of roles, in the view of the scenarios created for that operation to happen according to its strategic goals. Under this perspective, an organizational analysis is crucial since from this approach, the constraints related to the environment in which the company operates can be brought out, its structure, its strategic decisions, its ties with customers and suppliers, i.e. aspects that inevitably modulate tasks and, consequently, the work activities (Abrahão et al., 2009; Falzon, 2004; Guérin et al., 2006).

\subsection{Methods and procedures}

Data was initially collected in order to understand the overall functioning of the company, the determining factors and the social and economic context that surrounds the decision concerning the investment planning and the system the company operates. These data were collected through semistructured interviews with the different levels of the organizational structure in a top-down process. Concomitantly, the documentation covering the history of the company was analyzed, as well as its formal structure and the composition of the different management departments, their assignments and their articulation in the formal planning of the operation. Data collected from the official city website related to system performance were also analyzed and discussed to detect the company's excellence level among other system operators and also the company's challenges in pursuit of its excellence. These data are basically presented based on historical comparisons with both system and other system operators from 2000 to 2012.

Subsequently, the people responsible for each of the departments were interviewed and, in this process, qualitative and quantitative data was obtained, which contributed to enrich the researchers' representations about the company's operation, as well as the difficulties related to the operation management and to the nature of the employees' demands as to the social and medical services.

The analysis of all these data allowed the formulation of the study hypothesis, supported the definition of the scope of the study and the choices of the bus lines to be analyzed in order to understand the conditions under which the drivers actually performed their work activity. The lines that could reflect a sample comprising the different conditions to which the crew was submitted at different times of the course were defined. We then decided to collect data covering the traffic flow during working hours.

For systematic observations, 14 hours and 49 minutes of driver's activity were performed along 17 trips. The observation occurred in 10 different buses (in 7 cases the observations continued on the same bus, round trip). Data was collected on 4 buses with manual transmission and 6 with automatic transmission. The period of analysis included: 6 trips during the morning peak period, 3 trips during the afternoon peak, 4 trips during a period of low flow, 3 trips after the morning peak period, 1 trip before the afternoon peak period. Such observation involved seven different bus lines, 5 of them being cross-sectional and the other 2 of them radial type. The qualitative and quantitative data were articulated to allow understanding and explaining the elements that define the company's excellence.

\section{Results and analysis}

Both study results and analysis emphasize the importance of considering a range of variables and their interrelationships to understand the challenges related to ensuring excellence in transport services production. This discussion is focused on understanding the company's context that directly or indirectly shapes the bus drivers' work.

\subsection{The company's pursuit of excellence in numbers}

Excellence concerning the operation of this company means: quality of the service provided, economy and worker's health (drivers, collectors, company's internal staff), considering that this assessment is based on different indicators. Regarding the quality of the service provided, its strategic decision in order to pursue excellence is shown especially related to indicators of the city's transport system.

When compared with system average values and with other companies, there are clear differences. For example, the company's fleet has features that are unique and positive in terms of quality of the vehicles as compared with other companies, not only for the users but also for the drivers.

The fleet system has few air-conditioned vehicles (23.2\%), with few automatic gear (22.8\%), roughly $40 \%$ of vehicles with affordability and approximately $54 \%$ without a front engine (see Table 1). However, the company has significantly higher values in all these items: $44.0 \%$ of its vehicles have air conditioning, $46.6 \%$ of vehicles provide accessibility, 
73\% have automatic gear and 73\% do not have a front engine (rear or central engine). Furthermore, given that the company has $20.7 \%$ of the total vehicle fleet, its contribution is always significant in each item individually, with $150(39.2 \%)$ out of the 383 air-conditioned vehicles, 159 (46.6\%) out of 659 with accessibility, 249 (66.2\%) out of 376 with automatic gear and $249(27.8 \%)$ out of 896 without a front engine. This quality of the fleet is not the result of a requirement of the system or contractual obligation; it arises from strategic decisions to maintain service excellence. Air-conditioning, automatic gear and rear engine vehicles impact both service quality and the workers' activity.

As for performance, an important indicator for public transportation is the level of compliance of trips, and the company's history data is always above the system average and the other operators' average (see Table 2). The company was best placed for this index almost every year. Note that this result cannot be achieved without the engagement of the operation, i.e., it requires the action of drivers to ensure that performance.

As for service quality, a relevant indicator is the rate of users' complaints, which in this case is measured by the number of passengers transported by the amount of claims (see Table 3). The company has always had a higher number of passengers per claim, which indirectly demonstrates greater user satisfaction in relation to the services provided by the company.

As a consequence, this quality level and user satisfaction obtained through strategic decisions is also observed in direct and indirect workers' actions, as is the case of a longer driver training. There are also initiatives focused on better service to users, coordinated actions for regulating the temporal constraint and management of unpredicted events that demonstrate concerns with drivers' activity related to quality and excellence (see 3.5).

These elements emphasize the results of decisions based on strategies that seek service excellence and quality. However, it is certainly a favorable condition, but not sufficient for ensuring quality and excellence operation (end-line). These conditions need to reflect these strategies in the operation, not only extending to workers (in the sense of comfort, safety, health, training, etc.), but some even require the worker's engagement. This becomes evident, for instance, with many drivers having prior knowledge of the

Table 1. Company's fleet in 2010.

\begin{tabular}{|c|c|c|c|c|c|}
\hline Vehicle characteristics & Company's vehicles & $\begin{array}{l}\text { Company's } \\
\text { vehicles regarding } \\
\text { company's fleet }(\%)\end{array}$ & System vehicles & $\begin{array}{l}\text { Company's vehicles } \\
\text { regarding system } \\
\text { vehicles }(\%)\end{array}$ & $\begin{array}{l}\text { System vehicles } \\
\text { regarding system } \\
\text { fleet }(\%)\end{array}$ \\
\hline With air conditioning & 150 & 44.0 & 383 & 39.2 & 23.2 \\
\hline With accessibility & 159 & 46.6 & 659 & 24.1 & 39.9 \\
\hline With automatic gear & 249 & 73.0 & 376 & 66.2 & 22.8 \\
\hline With manual gear & 92 & 27.0 & 1,274 & 7.2 & 77.2 \\
\hline With front engine & 92 & 27.0 & 754 & 12.2 & 45.7 \\
\hline $\begin{array}{l}\text { Without front engine } \\
\text { (i.e. rear or central engine) }\end{array}$ & 249 & 73.0 & 896 & 27.8 & 54.3 \\
\hline fleet & 341 & 20.7 & 1,650 & & \\
\hline
\end{tabular}

Table 2. Index of compliance of trips.

\begin{tabular}{|c|c|c|c|c|c|c|c|c|c|c|c|c|c|}
\hline & \multicolumn{13}{|c|}{ Year } \\
\hline & $\begin{array}{c}2000 \\
(\%)\end{array}$ & $\begin{array}{c}2001 \\
(\%)\end{array}$ & $\begin{array}{c}2002 \\
(\%)\end{array}$ & $\begin{array}{c}2003 \\
(\%)\end{array}$ & $\begin{array}{c}2004 \\
(\%)\end{array}$ & $\begin{array}{c}2005 \\
(\%)\end{array}$ & $\begin{array}{c}2006 \\
(\%)\end{array}$ & $\begin{array}{c}2007 \\
(\%)\end{array}$ & $\begin{array}{c}2008 \\
(\%)\end{array}$ & $\begin{array}{c}2009 \\
(\%)\end{array}$ & $\begin{array}{c}2010 \\
(\%)\end{array}$ & $\begin{array}{c}2011 \\
(\%)\end{array}$ & $\begin{array}{c}2012 \\
(\%)\end{array}$ \\
\hline COMPANY & 95.4 & 96.9 & 97.5 & 98.2 & 98.3 & 97.7 & 95.2 & 94.6 & 93.4 & 95.3 & 95.3 & 95.0 & 92.5 \\
\hline OTHERS & 95.2 & 94.7 & 96.7 & 96.9 & 96.8 & 96.4 & 94.7 & 92.6 & 92.5 & 92.3 & 93.6 & 93.4 & 91.9 \\
\hline SYSTEM & 95.2 & 95.1 & 96.9 & 97.2 & 97.2 & 96.7 & 94.8 & 93.1 & 92.8 & 92.9 & 93.9 & 93.8 & 92.0 \\
\hline
\end{tabular}

Index of compliance of trips: number of fulfilled trips by the total number of trips.

Table 3. Rate of claims.

\begin{tabular}{lcccccccccccccc}
\hline & \multicolumn{10}{c}{ Year } \\
\cline { 2 - 13 } & 2000 & 2001 & 2002 & 2003 & 2004 & 2005 & 2006 & 2007 & 2008 & 2009 & 2010 & 2011 & 2012 \\
\hline COMPANY & 48.961 & 60.730 & 65.076 & 63.691 & 65.945 & 65.710 & 64.005 & 61.246 & 32.950 & 34.953 & 28.686 & 20.926 & 15.566 \\
OTHERS & 29.894 & 35.436 & 31.124 & 31.563 & 37.825 & 43.836 & 52.088 & 49.996 & 32.094 & 28.027 & 21.961 & 15.652 & 12.166 \\
SYSTEM & 31.164 & 38.846 & 35.140 & 35.240 & 41.397 & 47.339 & 53.912 & 51.836 & 31.688 & 28.488 & 22.721 & 15.980 & 12.486 \\
\hline
\end{tabular}


passengers to be taken at the next stop, depending on the weekday and time, so as to anticipate and to take specific decisions if users are elderly or need special attention. The drivers find themselves facing the work strategies related to service relationship, i.e., concerned about the relationship with the user which, of course, it may also happen in other companies in this segment, but in that case this highlights and reinforces the quality and excellence in operation.

\subsection{The company's challenges in the pursuit of excellence}

However, it was noticed that there are in fact ambiguous issues faced by the company. Because it is a public organization, the company also has other roles in the system, such as providing better conditions (especially financial ones) to other companies that compose the public transport system. For instance, the company accounts for the longer lines and less advantageous (from an economic perspective); besides, the company has the most dangerous lines (they present a significantly higher assault rate than the system average, see Table 4).

Regarding economy, the classic indicators are profitability and investment capacity. Their role is to structure the operating system, to distribute the revenue according to the index of passengers per kilometer (IPK), which is higher in this company than in the other transportation companies. Furthermore, it should generate surplus funds for investment in the system itself, so as to improve service quality indicators.

Moreover, the company lines present the largest number of passengers transported per kilometer which, at first sight, should be positive because this means more revenue. However, the system operation rule was formulated in order to equally distribute the revenue from the system as a whole, which generates a financial transfer of the company to other operators. In 2012, the company had an index of passenger per kilometer 23\% higher than the average of the system while the average of the other operators was only $96 \%$ over the average of the system (see Table 5).

Although this information is not considered by the system, it contributes to the passenger's positive perception in the evaluation of the company's excellence. In order to minimize the situation, drivers elaborate operational strategies consisting of regulatory processes that are able to retard or to advance their vehicles, especially when they realize that traffic or an incident on the road is changing the schedule initially planned.

The quality of the fleet and its standardization in relation to the facilitation of maintenance activities and the elements that result in quality for the passenger and for the driver (e.g. rear engine, low floor, air conditioning, brake assist, automatic transmission) have a strong impact on the three sets of elements that form the quality concept - for the user, for the shareholders (and taxpayers) and for the worker. Occasionally, the increased investment in quality for the user or for the driver, with automatic transmission, for instance, could mean reduced quality of economic performance and this is the critical point in defining the company's strategy: the ideal combination of the indicators temporally planned.

One of the direct financial impacts is to sustain an appropriate quality in the operation level, which reflects the failure rate for periodic inspections (see Table 6). In general, the company's failure rate is close to the system average. However, even

Table 4 . Rate of assaults in relation to the average system.

\begin{tabular}{|c|c|c|c|c|c|c|c|c|c|c|c|c|c|}
\hline & \multicolumn{13}{|c|}{ Year } \\
\hline & $\begin{array}{c}2000 \\
(\%)\end{array}$ & $\begin{array}{c}2001 \\
(\%)\end{array}$ & $\begin{array}{c}2002 \\
(\%)\end{array}$ & $\begin{array}{c}2003 \\
(\%)\end{array}$ & $\begin{array}{c}2004 \\
(\%)\end{array}$ & $\begin{array}{c}2005 \\
(\%)\end{array}$ & $\begin{array}{c}2006 \\
(\%)\end{array}$ & $\begin{array}{c}2007 \\
(\%)\end{array}$ & $\begin{array}{c}2008 \\
(\%)\end{array}$ & $\begin{array}{c}2009 \\
(\%)\end{array}$ & $\begin{array}{c}2010 \\
(\%)\end{array}$ & $\begin{array}{c}2011 \\
(\%)\end{array}$ & $\begin{array}{c}2012 \\
(\%)\end{array}$ \\
\hline COMPANY & 148 & 170 & 181 & 84 & 79 & 99 & 140 & 138 & 107 & 137 & 168 & 151 & 96 \\
\hline OTHERS & 91 & 86 & 82 & 109 & 107 & 102 & 95 & 93 & 100 & 92 & 87 & 92 & 102 \\
\hline
\end{tabular}

Rate of assaults: number of assaults per 10,000 travels.

Table 5. IPK in relation to the average system.

\begin{tabular}{lcccccccccccccc}
\hline & \multicolumn{10}{c}{ Year } \\
\cline { 2 - 13 } & $\begin{array}{c}2000 \\
(\%)\end{array}$ & $\begin{array}{c}2001 \\
(\%)\end{array}$ & $\begin{array}{c}2002 \\
(\%)\end{array}$ & $\begin{array}{c}2003 \\
(\%)\end{array}$ & $\begin{array}{c}2004 \\
(\%)\end{array}$ & $\begin{array}{c}2005 \\
(\%)\end{array}$ & $\begin{array}{c}2006 \\
(\%)\end{array}$ & $\begin{array}{c}2007 \\
(\%)\end{array}$ & $\begin{array}{c}2008 \\
(\%)\end{array}$ & $\begin{array}{c}2009 \\
(\%)\end{array}$ & $\begin{array}{c}2010 \\
(\%)\end{array}$ & $\begin{array}{c}2011 \\
(\%)\end{array}$ & $\begin{array}{c}2012 \\
(\%)\end{array}$ \\
\hline COMPANY & 124 & 121 & 122 & 124 & 126 & 125 & 122 & 121 & 123 & 123 & 122 & 123 & 121 \\
OTHERS & 95 & 95 & 95 & 94 & 94 & 95 & 95 & 95 & 94 & 95 & 95 & 95 & 96 \\
\hline
\end{tabular}

IPK (Index of passengers per kilometer): number of passengers per kilometer. 
Table 6. Inspection failure rate.

\begin{tabular}{|c|c|c|c|c|c|c|c|c|c|c|c|c|c|}
\hline & \multicolumn{13}{|c|}{ Year } \\
\hline & $\begin{array}{c}2000 \\
(\%)\end{array}$ & $\begin{array}{c}2001 \\
(\%)\end{array}$ & $\begin{array}{c}2002 \\
(\%)\end{array}$ & $\begin{array}{c}2003 \\
(\%)\end{array}$ & $\begin{array}{c}2004 \\
(\%)\end{array}$ & $\begin{array}{c}2005 \\
(\%)\end{array}$ & $\begin{array}{c}2006 \\
(\%)\end{array}$ & $\begin{array}{c}2007 \\
(\%)\end{array}$ & $\begin{array}{c}2008 \\
(\%)\end{array}$ & $\begin{array}{c}2009 \\
(\%)\end{array}$ & $\begin{array}{c}2010 \\
(\%)\end{array}$ & $\begin{array}{c}2011 \\
(\%)\end{array}$ & $\begin{array}{c}2012 \\
(\%)\end{array}$ \\
\hline COMPANY & 16.4 & 51.2 & 17.9 & 16.9 & 7.2 & 8.3 & 12.7 & 17.6 & 13.6 & 15.7 & 17.4 & 20.6 & 22.2 \\
\hline OTHERS & 9.0 & 39.5 & 23.8 & 10.3 & 4.8 & 10.8 & 21.4 & 16.2 & 14.7 & 14.8 & 17.8 & 23.5 & 20.6 \\
\hline SYSTEM & 10.4 & 42.4 & 22.7 & 11.7 & 5.3 & 10.4 & 19.6 & 16.6 & 14.7 & 15.5 & 18.2 & 23.1 & 21.4 \\
\hline
\end{tabular}

Inspection failure rate: number of disapproved vehicles by inspected vehicles.

so, in recent years, although it is not the best in this regard, it has kept better results. Part of this improvement is credited to a change in the interaction between drivers and maintenance staff, who began exchanging more consistent information to facilitate vehicle repairs.

Even with these issues, which means huge company disadvantages, the strategies linked to improve vehicle (both items reflect in quality and a relative low inspection failure rate), greater emphasis on the training of drivers are followed by a service recognized by the population, which can be indirectly proven by the high rate of complaints by passengers, as shown before.

\subsection{The social support and the organized values that guide the company}

The Company's Social Service is the first place where the workers are listened to, where they have the freedom to express their grievances and personal problems; it is described by workers as a facilitating department. This department's focus is to assist workers with matters related to social relations, particularly as regards conflicts, fears and anxieties. The greatest complaint is associated with difficulties in interpersonal relations (with management, colleagues, customers, traffic, etc.). They say that conflict is often associated with the allocation of working hours. "There is competition towards the best schedules and those who are not assigned them get upset for not finding any justification for such a decision" (from interviews).

The robberies that happen inside the bus, often keeping the driver and the conductor hostages, do not become a part of the work accidents statistics. Robberies are currently considered one of the possible events responsible for emotional destabilization of the team working in the operation. The crew is trained not to react in those situations. Working under these conditions and maintaining excellence requirements involves hiding fears and submitting to the profession mishaps, remaining friendly with all, not knowing if the next user is a burglar or not.

In accident situations, when there is a victim, social service workers are sent to the location. The company maintains two people from this department on permanent duty, even on weekends. Serious accidents are not many, according to the company, and this is the result of a sustained policy for prevention actions.

The organization's strategy is to show that the drivers are not alone, that there is a structure behind them and that this structure is considered co-responsible for the mistakes (from interviews).

Thus, in these situations, the driver learns that there are several possible reasons for the accident, such as maintenance, better training and the pressure coming from the hierarchy. This assistance aims to strengthen and to relieve the worker. The company's position is that accidents are not intentional: "a deliberate crash is rare, but it can happen" (from interviews).

The drivers are not financially responsible for accidents that occur with the vehicle under their responsibility and third parties' ones. However, when a driver 'crashes' the bus more often than considered reasonable, he will probably be dismissed. Nowadays, an incentive policy is under study, to motivate "good" drivers, which are those who go through longer periods without taking part in accidents or damaging the vehicle, or those causing the fewer number of damages to their vehicles in a given period.

To cope with this variability, which is repeated throughout the days and years is the challenge posed to drivers in order to ensure service excellence, for their own and the company's image. There is always an action to be undertaken towards directing the focus towards strategic decisions, as quality of work is a central aspect. The quality of these actions depends on an organizational congruence that considers different aspects such as the work done by its employees, the inclusion of citizenship in the discussion around the quality of mobility, and technological development.

\subsection{Workers}

Aiming to understand who the main actors responsible for the visibility of the company's excellence are, we will discuss their characteristics and the role of the company's organizational standards in this regard. 
At the time of data collection, the operational department counted on 799 drivers (active and on leave), 622 of those were active.

Figure 1 shows a very interesting distribution that allows inferring a low turnover trend, as many of the drivers remain in the company for a relatively long period. The admission of new drivers and discussions carried in the company corroborate the tendency to favor their permanence in the company and to provide a team of stable and experienced drivers. Privileging a permanence policy can also contribute to the maintenance of the existing organizational values and the consolidation of excellence sought by the company.

There are no reports providing data concerning the distribution of drivers considering their time in the company. In some cases, the time the driver has worked for the company should be considered, but there are often changes in the job position via tender, not to mention those drivers who joined the company after having previous driver experience.

Collecting data regarding the age of the drivers and leaves of all kinds at the time of collection

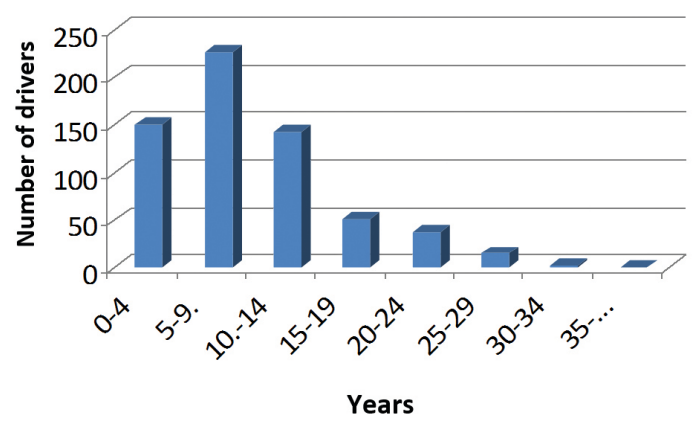

Figure 1. Drivers divided by length of employment in years. allowed us to identify some correlations which are discussed below (Figure 2).

Interestingly, the incidence of absenteeism begins in the age group between 30 and 35. However, the increase in the age groups above 50 is remarkable, once in terms of percentage, these absences are much higher than in the other groups. This could be due to the kind of work performed along with the age factor, mainly because bus drivers in these age groups have worked over a longer period of their careers in conditions that would favor the emergence of diseases caused by repetitive motion, maintenance of prolonged bad posture, exposure to hot weather and noise, as well as to situations involving anxiety.

These data corroborate the information concerning length of service and confirm the drivers' tendency to remain in the company. According to the reports obtained through this study, they feel as if they were part of the process of building and maintaining the excellence status achieved by the company, in addition to promoting the preservation of organizational memory, particularly with regard to the maintenance of the values associated with excellence.

Additionally, the workers are proud of working for the company which is something not only recognized among them and their peers, but also a recognition by society, which indirectly demonstrates once again the building of a quality and excellence long-term strategy.

Hiring occurs under the Brazilian laws for long term contracts, via public tender. When necessary, the company provides guidance for those responsible for running the tender, specifying the content of the written and practical tests, as well as the prerequisites for the candidate's selection. Depending

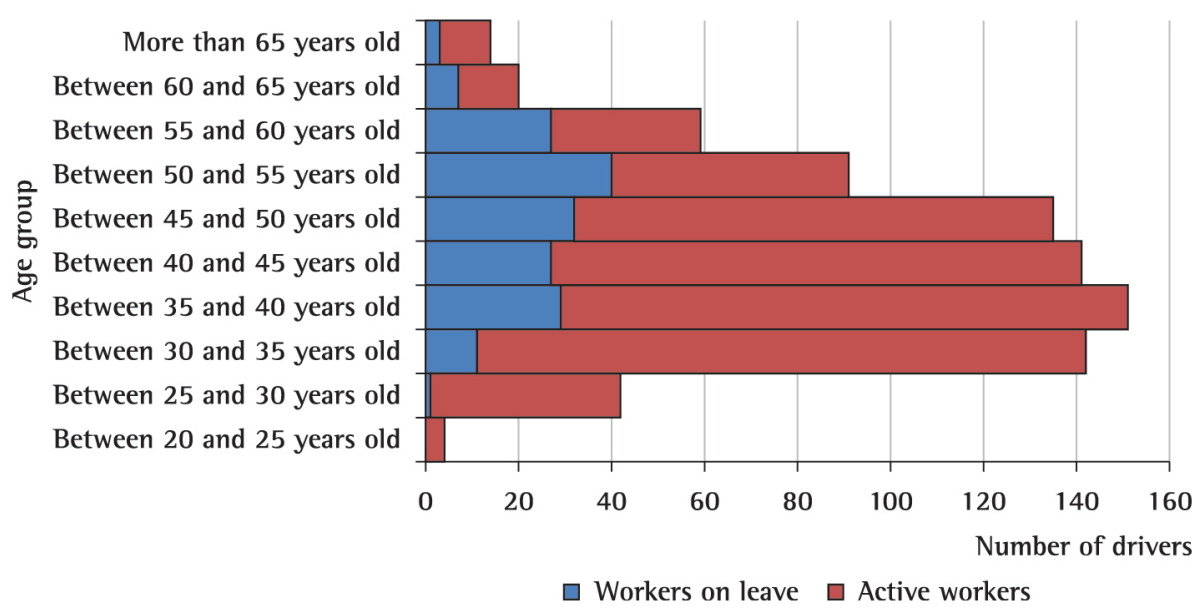

Figure 2. Bus drivers presented by age group - active and on leave. 
on the need, the prerequisites of the drivers tender present modifications as a way to ensure, at times, a longer list of potential candidates, better qualified for the profession. In general, these requirements are associated with education level, length of professional experience as a bus driver or similar, among others. Additionally, the collectors can ascend to a driver position, through a selection process.

Besides the capacity training offered at the time of hiring, periodic trainings are also provided to bus drivers. These trainings are always performed during off-peak working hours. The operational area usually defines the training goals and the list of drivers that will take part in these trainings. Situational trainings are also planned, aiming at raising awareness among drivers about the reality and diversity of passengers, for example, wheelchair passengers and the visually impaired.

The company adopts recognition policies geared to workers who are spotted for their collective and individual production. Profit sharing programs are established and, since the early 2000s, they have been increasing worker's commitment. Among other factors, the programs consider several variables such as absenteeism, accidents and breakdowns, among others. They are composed of individual and collective assessment mechanisms and the award parameters result in benefits distribution linked to social and economic results.

The base salary is the same to the entire category of drivers of the city's public transport system. However, according to information gathered during the interviews,

the private companies' drivers are interested in participating in the selection process. They want it because of the company's history, its social role and the structure it provides. The salary is the same within the category, but there are differences such as the existence of a health department in the company, a very active social area, recreational facilities, dentist services, capacity trainings and work schedules that are more flexible (from interviews).

If necessary, the job contract can be terminated.

When analyzing the company's operation, it is possible to identify the differences in relation to other companies, which leads drivers to seek work in the company, as well as explaining the low turnover rate found. The work recognition policy associated with the support offered through training and the support provided by medical and social assistance results is drivers working towards the maintenance of the excellence image achieved throughout its history.

\subsection{Systematic observations}

Just as the features mentioned above have a significant influence on the drivers' work, the technology available for drivers is also of paramount importance to the excellence issue and to the quality of the drivers' work. For vehicles, we found a significant correlation between working conditions and the quality of buses. In this case, we considered that the vehicles are indeed designed as buses, since they are often adapted trucks, and incorporate technologies that increase comfort, both for passengers and the drivers.

As example of work effort, vehicles with manual transmission require repetition of movements. The data presented below (Figure 3) illustrate the repetition of movements along a route and show a great musculoskeletal demand throughout the day. Over the years, degeneration of this muscle group is expected. During 48 minutes of observation, starting

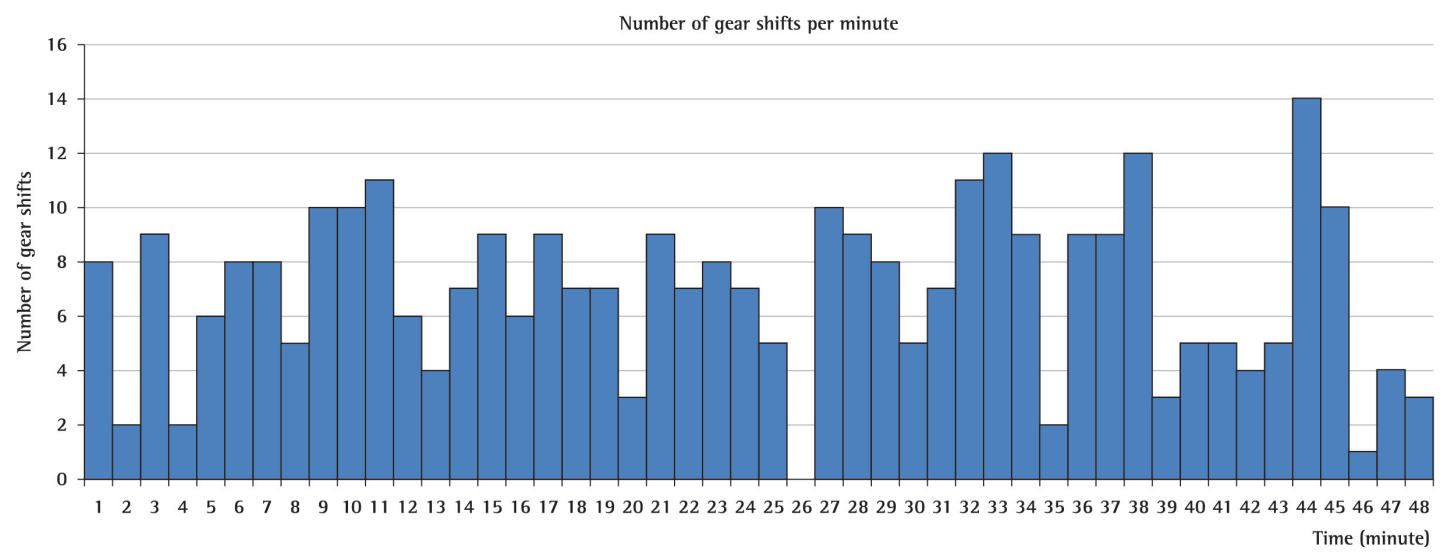

Figure 3. Number of gear shifts per minute of a 48-minute trip. 
at 12 hours and 50 minutes, there were 330 gear shifts.

The repetition of movements during a trip illustrates the great musculoskeletal demand throughout the day and over time it can be a determining factor for the onset of musculoskeletal problems. Note that it is not just the repetition of gestures that can be problematic, but also the adoption of bad posture and postural immobility over time (Troup, 1978; You et al., 1997). Efforts related to manual gear is something that needs to be always discussed in order to reinforce the need to rethink minimum comfort conditions for drivers, which are not yet regulated in the country.

The conditions of the roads and of the traffic, the maintenance of the job position associated with its configuration, the demand for attention and good posture over time - forcing the muscle groups of the neck, back, shoulders - help to justify medical leaves indicated by the medical service, relative to musculoskeletal problems. These are the most frequent reasons for absences related to musculoskeletal disorders (RSI / WMSD): neck ache, back ache, spine degeneration, bursitis, carpal tunnel syndrome and knee problems resulting from the manipulation of the manual transmission and from obesity (Alperovitch-Najenson et al., 2010; Anderson, 1992; Okunribido et al., 2007; Szeto \& Lam, 2007). In the case of vehicles with front engines, there is greater exposure to noise, heat and vibration, which can increase the risk of hearing disorder, hypertension, and as it has been very prevalent in the category, varicose veins (Blood et al., 2010; Bovenzi \& Zadini, 1992).

We have identified problems of other sorts that are also worrisome, such as medical leaves for psychiatric problems, as well as the consequences of work accidents. Regarding impacts deriving from anxiety-related situations experienced by drivers, we have no conclusive evidence to link them with health issues, despite the evidences that musculoskeletal disorders such as RSI / WMSD are common among them. We found further evidence that psychological distress is quite prevalent in the category. An increase in complaints related to services related to workers' health and welfare is also reported.

Moreover, they have to deal with robberies, often involving guns, with the most diverse forms of aggression and dispute that may occur in association with other drivers, besides the risk of injuring a passenger or other drivers, pedestrians and cyclists, which is part of their journey (Gobel et al., 1998; Tse et al., 2006).
Another point worth mentioning is that, unfortunately, the drivers' work tends to become the adjustment variable of the system, especially with regard to the management of time (Abrahão et al., 2009). Its expression is manifested in the change in the break times, especially during peak hours, as they are substantially reduced. This fact itself is not a problem, but it can be one if the reality of the drivers' work is not considered and if the conditions conducting to the development of chronic fatigue and different types of pathologies are not avoided (Gilbert-Ouimet et al., 2011).

\subsection{Other important aspects gathered by systematic observations}

\subsubsection{General characteristics of the system and the task determining factors}

Also to be highlighted is that, if on the one hand the driver is a regulator, on the other hand he lives under constant conflict situations and pressures from the organization and from the system management to maintain the service level; this is expressed in indicators that can often be analyzed without a more systemic view that considers the complexity of such reality. Taking all these aspects into account, this is a major challenge for both the company and the system management.

The regulatory agency has a remote monitoring system. In general, each vehicle is checked at three distinct points per trip. There is a tolerance of 4 minutes at the electronic monitoring check points, making vehicle arrive at most 4 minutes late or in advance.

On average, 2,287 trips are held per day distributed in 567 tables through which the crews of each line are set. On Saturdays, the company operates with $60 \%$ of its fleet and on Sundays, with only $40 \%$. The transport system morning peak is due to the amount of passengers, which generally requires 301 cars in operation. The afternoon/evening peak is due to the traffic usually requiring 298 cars in operation.

During the operation, monitors located in the terminals control the progress of the service. Drivers are responsible for making decisions in the face of events. For example, when necessary, a vehicle is moved from one zone to another or directed from one line to another.

The drivers are not penalized for being late, but are penalized for arriving earlier. According to the operation planners, the times are so well established that, theoretically, it should not be possible to arrive in advance. 
The drivers often complain about the planned times. They say that these times are too tight, and cannot be carried out. The Planning Department asks for these delay events to be reported in the trip report so as to consider them to make the necessary adjustments to the times, yet they are rarely reported by the drivers.

\subsubsection{The passenger: a determining factor for building excellence}

In recent years, there have been significant changes in the profile of the system passenger as an evident process of social inclusion. The number of exempt passengers have notedly become diligent users of this mean of transportation, such as the elderly, generate different impacts on the system, from costs to the operation itself.

The company counts on a consumer care service. Through it, the user is able to request information, make compliments, suggestions or complaints. In case of problems with vehicles, the user is asked about the location, date (if possible, the time), name of the line, direction of travel and license plate. There are two kinds of complaints, the valid and invalid ones, i.e., those which have been proven to be true or not. "Even when the claims are baseless, they are considered by the company" (from interviews).

On average, there are 200 complaints per month. From the workers point of view,

if confronted with the number of transported passengers [270.000/day, i.e. 6.500.000/month], [the complaints] are few ... and there was an increase in the channels available for complaints" (from interviews).

Once the company receives the complaint, the employee is involved in the decision on how appropriate the complaints are. "The crew is always heard in order to provide the best answer to the passenger" (from interviews).

Interestingly, the company analyzed has the highest gross number of complaints over the years, but in comparison to the amount of passengers transported, there are few complaints, especially if we consider the private consortia companies rates.

The analysis of the most recurrent complaints focus on issues directly or indirectly related to the system sizing. Accordingly, peak periods can be considered the times when there is greater time pressure and, at the same time, a higher variability, making it difficult to work and causing constraints to the drivers.

Furthermore, these periods also interfere with the driver-passenger interaction, since the user is also impacted by the system conjuncture, causing delays in their personal schedules and dissatisfaction that can be eventually reported, blaming the bus drivers for such a situation. The user will rarely have enough information to report the real cause of the events that happen unexpectedly. Thus, some issues may be associated with the moods and behavior of the driver and others may be beyond governance. However, note that an analysis of these issues from the perspective of the drivers' work leads us to infer that one of their main tasks concerns the relationship with passengers, as well the management of events that occur inside the bus. Driving a passenger vehicle also requires the driver to consider the diversity of the population and their desires, within the limits imposed by the characteristics of the operation.

We do not intend to build a relationship of cause and effect of the probable reasons that subsequently generated complaints at the moment. It is possible to present other interpretations for each indicator which, as mentioned earlier, can be directly or indirectly related with time pressures and their sizing system. In a first approach to these facts, we will present some explanatory hypotheses derived from observing activities and drivers' utterances:

- Impossibility of disembarking through the exit door: in some cases, it can be caused by the masking of information provided by the light and acoustic signal pressed by the passenger at the bus stop. Some vehicles, especially front-engine ones, feature a high level of noise that can impair the detection of the acoustic signal. Moreover, in the early morning and late afternoon, there is solar incidence directly on the panel, which affects the driver's vision, and can make it difficult to visualize the light signal on the panel.

- Failure to complying with the schedule: Once the planned schedule cannot cover all the unforeseen events, the drivers have to constantly deal with the pressure to meet the schedule. The variables and events that are presented throughout the operation escape their governance, so all there is left to be done is trying to adjust to the facts, which sometimes result in conflict.

- Accelerating before embarking/disembarking is concluded: this can be one of the consequences of the lack of time management between what was planned and reality. Usually, this type of procedure is an attempt to distribute users, when the driver realizes there is an emptier vehicle behind him that will do the same itinerary.

- Stopping off the bus stop: This can be caused by various reasons, such as bus queues or other vehicles at the stop. 


\section{The driver's activity: an activity to provide excellence}

The bus drivers' work is determined by conditions that are external and internal to the organization. It is possible to work under a two-dimension perspective that mediates excellence: the first concerns the conditions that are external to the company, and the second, the norms and rules that organize the company internally.

Among the external factors that influence operation excellence, we have found different elements acting differently and over which the company has little power: the quality of the fleet - this decision is taken in accordance with external demands on when and how to proceed with the fleet's renewal; system strategic planning - creation or modification of lines, diversion of routes, allocation of lines to companies from other consortia and dimensioning of lines (frequency, type of car); the revenue of the company's transportation system - meaning the differential cost in the revenue sharing; traffic - a punctuality mediator that influences the user's evaluation; the quality of roads - which is very irregular and interferes with speed, maintenance and, consequently, with the punctuality during the journey; unexpected events - robbery, accidents among others, passengers' evaluation which is performed considering punctuality, people's criticism and interpersonal relations with motorists.

Although these factors go beyond the action power of the company, it is ultimately the drivers' obligation to build operational ways to cope with this variability that is inherent to their work. Thus, throughout the work day, drivers create operational strategies to overcome constraints arising from various factors, such as speed, traffic, irregular routes, and punctuality. These strategies are regulatory processes performed by them in an attempt to meet the demands of the tasks. And by managing this process, one of the dimensions of the drivers' skills within the excellence frame is manifested.

Regarding the internal determining factors, they arise from decisions that are intertwined and are of organizational and political nature such as: changes in the company's management, organizational determining factors, the acquisition of new vehicles, operational capacity, time management in the lines to prevent fatigue at work, and the regulatory strategies to maintain the quality of the operation (Abrahão $\&$ Torres, 2004).

This interdependence between such disparate factors leads us to assert that working under the perspective of achieving and maintaining high excellence standards goes beyond planning for proper sizing and renewal of the fleet. Excellence is achieved through a service that also requires inter-social relations, many of which, not to say the most, result from the driver's action. Therefore, his work can also be considered as a system regulator, since the driver must manage the times imposed by the system and the most diverse types of events that are part of reality (Lima, 1994). In addition, there are a number of requirements by passengers such as their expectations regarding the quality of service.

The data analysis has shown that the driver's activity is permeated by unforeseen events that occur randomly and, in some situations, if not most, the expected action is to anticipate incidents and accidents. The driver must act preemptively (Salmon et al., 2011). The right management of such situations reveals their different skills. One is its ability to manage the various events, with which they are confronted during their workday in order to ensure efficiency and effectiveness in transporting people. However, these are difficult things to be measured and valued because, when successful, their action is invisible (Daniellou, 1996), not registered. This situation is due to the fact that classic management indicators do not consider alertness able to cover reality, there is little or no room for the work reality to be evident.

Goldstein et al. (2002, p. 121) argue that the concept of service supports mediate between the service user needs and the company's operational strategy. Besides, as state Grönroos \& Ojasalo, service productivity is related to:

(1) how effectively resources input into the service (production) process are transformed into outputs in the form of services (internal efficiency), (2) how well the quality of the service process and its outcome is perceived (external efficiency or effectiveness) and (3) how effectively the capacity of the service process is utilized (capacity efficiency) (2004, p. 414).

In this sense, all the effort promoted by company's bus drivers (developing work strategies and operation regulation performed by the drivers through their actions) is observed to positively impact the company's operation and, at the same time, to express the compromise between the objectives of the activity and the population needs (Cunha \& Lacomblez, 2006). This engagement changes both the service evaluation from the perspective of those who use the system (Zarifian, 2001) and service relation (Hubault \& Bourgeois, 2001).

\section{Conclusion}

Ensuring an organizational alignment that integrates the needs of the population, financial issues, techniques and the different types of work developed by the company, contributes to 
health, preventing work-related diseases which are very prevalent in this profession. Moreover, it is important to provide conditions in order to obtain professional development, such as constant training and recognition of drivers' role in order to assure citizenship. These aspects compose an excellence framework. Continuously monitoring and improving these aspects is fundamental to achieve and to maintain excellence.

The excellence attributed to the service provided by the company is one of the pillars of the support offered to its employees at different times in their lives. Therefore, the data indicate an effort and organizational alignment that reaches different structures in the company, aiming at the construction and maintenance of excellence.

The question of establishing what degree of quality is expected from public transport is an issue that should be regarded as a political-strategic decision, involving different social actors who, in one way or another, affect the citizenship issue providing mobility for the population. Hence, it goes far beyond timing a route schedule; it is necessary to consider the different needs and the differences among users, as well as a conceptual expansion of what the mobility service is. This is why providing this service with excellence depends on areas outside the company's governance, in its strict sense. There is a great challenge for the company: to make the issues that arise in the operation and system's day to day visible to the public spheres of power.

Another question must be asked: is it possible to operate with service excellence, but not to do the same in relation to the operation? In this case, one has a tri univocal relationship among service quality, economic and financial issues, the promotion of professional development and workers' health. If there is no operation excellence, there will be no service excellence, and operation excellence requires work excellence. Furthermore, we emphasize that the service quality depends on a systematic alignment, covering strategic decisions from the management of the transport system and organizational governance within the company that modulate the operation itself. The contact with citizens is the last instance of service's relationship, the quality of which is modulated by the way the driver acts.

In this perspective, to provide conditions that enable service excellence, it is important to maintain and to strengthen the company's policies to provide drivers and other workers, working conditions and professional and personal support aiming at the development of professional identity and health maintenance.
The quality of the fleet and its standardization, both in relation to the facilitation of maintenance activities and the quality elements for the passenger and the driver (rear engine, low floor, air conditioning, brake assist, automatic transmission) have a strong impact on the three sets of elements constitutes the quality for the user, for shareholders (and taxpayers) and for the worker.

Occasionally, the increased investment in quality to the user or to the driver (investment in technology, for example) can have significant financial impacts, at first. This is a critical point that concerns the definition of the company's strategy: the ideal combination of indicators temporally planned to conduct the company's management.

A company that offers a better quality public service, even when there is no requirement or obligation, demonstrates that it is possible to rethink and even to embed several issues addressed in this study that can mark the progress of the new guidelines for public policies to regulate public transport and the urban mobility system. This becomes more relevant in the current political and socioeconomic context of the country in which the study was conducted, which is rethinking how to provide public services to society with better quality and excellence. There are also evidences that the idea of excellence modulates the service logic, including the operation.

The objective of the study is mainly to highlight the company's positive policies. In this sense, the ergonomic work analysis approach contributed to reinforcing the correction of certain policies and also to helping to fight organizational errors that should be avoided. Certain elements were not analyzed in depth once the strategy point of view was the main goal. It was thus not always possible to get to the background in all aspects. However, identifying favorable conditions for a better quality service does not mean that the work situation is fully adequate. For example, it is always necessary to deal with an issue that is also the focus of ergonomics regarding the adequacy of the work against difficulties related to aging and illnesses of the population.

If there is no policy focused on both improving and achieving excellence, it undermines the competitiveness of companies that invest substantially in service excellence even when this is not envisaged by the regulation. In order to build a public agenda that focuses on quality service continuity, it is necessary to provide equity among service providers.

\section{References}

Abrahão, J. 1., Sznelwar, L. 1., Silvino, A., Sarmet, M., \& Pinho, D. (2009). Introdução à ergonomia: da prática à teoria. São Paulo: Blucher. 
Abrahão, J. 1., \& Torres, C. C. (2004). Entre a organização do trabalho e o sofrimento: o papel de mediação da atividade. Produção, 14(3), 67-76. http://dx.doi. org/10.1590/S0103-65132004000300008

Alperovitch-Najenson, D., Katz-Leurer, M., Santo, Y., Golman, D., \& Kalichman, L. (2010). Upper body quadrant pain in bus drivers. Archives of Environmental and Occupational Health, 65(4), 218-223. PMid:21186427. http://dx.doi.or $\mathrm{g} / 10.1080 / 19338244.2010 .486422$

Anderson, R. (1992). The back pain of bus drivers: prevalence in an urban area of California. Spine, 17(12), 1481-1488. PMid:1471006. http://dx.doi.org/10.1097/00007632199212000-00007

Blood, R. P., Ploger, J. D., Yost, M. G., Ching, R. P., \& Johnson, P. W. (2010). Whole body vibration exposures in metropolitan bus drivers: a comparison of three seats. Journal of Sound and Vibration, 329(1), 109-120. http:// dx.doi.org/10.1016/j.jsv.2009.08.030

Bovenzi, M., \& Zadini, A. (1992). Self-reported low back symptoms in urban bus drivers exposed to whole-body vibration. Spine, 17(9), 1048-1059. PMid:1411756. http://dx.doi.org/10.1097/00007632-199209000-00007

Cunha, L., \& Lacomblez, M. (2006). Driver activity in an ergologic sense: new territories of knowledge and intervention. In Proceedings of the Meeting Diversity in Ergonomics - IEA2006, Masstrich.

Daniellou, F. (1996). L'Ergonomie en quête de ses príncipes: débats épistémologiques. Toulouse: Octarès.

Falzon, P. (2004). Ergonomie. Paris: Presses Universitaires de France.

Gilbert-Ouimet, M., Brisson, C., Vézina, M., Trudel, L., Bourbonnais, R., Masse, B., Baril-Gingras, G., \& Dionne, C. E. (2011). Intervention study on psychosocial work factors and mental health and musculoskeletal outcomes [Special issue]. Healthcare Papers, 11, 4766. PMid:24917256. http://dx.doi.org/10.12927/ hсрар.2011.22410

Gobel, M., Springer, J., \& Scherff, J. (1998). Stress and strain of short haul bus drivers: psychophysiology as a design oriented method for analysis. Ergonomics, 41(5), 563-580. PMid:9613219. http:// dx.doi.org/10.1080/001401398186757

Goldstein, S. M., Johnston, R., Duffy, J., \& Rao, J. (2002). The service concept: the missing link in service design research? Journal of Operations Management, 20(2), 121-134. Retrieved from http://linkinghub.elsevier.com/retrieve/ pii/S0272696301000900 http://dx.doi.org/10.1016/ S0272-6963(01)00090-0

Grönroos, C., \& Ojasalo, K. (2004). Service productivity: towards a conceptualization of the transformation of inputs into economic results in services. Journal of Business Research, 57(4), 414-423. Retrieved from http://linkinghub.elsevier.com/retrieve/pii/ S0148296302002758. http://dx.doi.org/10.1016/S01482963(02)00275-8

Guérin, F., Laville, A., Daniellou, F., Duraffourg, J., \& Kerguelen, A. (2006). Understanding and transforming work: the pratice of ergonomics and transforming. Lyon: ANACT.

Hubault, F., \& Bourgeois, F. (2001). La relation de service: une convocation nouvelle pour l'ergonomie? In F. Hubault (Ed.), La relation de service, opportunités et questions nouvelles pour l'ergonomie (pp. 5-32). Paris: Octarès.

Lima, F. P. A. (1994). Medida e desmedida: padronização do trabalho ou livre organização do trabalho vivo? [Special issue]. Produção, 4, 3-17.

Okunribido, 0. 0., Shimbles, S. J., Magnus-Son, M., \& Pope, M. (2007). City bus driving and low back pain: A study of the exposures to posture demands, manual materials handling and whole-body vibration. Applied Ergonomics, 38(1), 29-38. PMid:17225292. http:// dx.doi.org/10.1016/j.apergo.2006.01.006

Salmon, P. M., Young, K. L., \& Regan, M. A. (2011). Distraction "on the buses": A novel framework of ergonomics methods for identifying sources and effects of bus driver distraction. Applied Ergonomics, 42(4), 602610. PMid:20883979. http://dx.doi.org/10.1016/j. apergo.2010.07.007

Szeto, G. P.Y., \& Lam, P. (2007). Work-related musculoskeletal disorders in urban bus drivers of Hong Kong. Journal of Occupational Rehabilitation, 17(2), 181-98. Retrieved from http://www.ncbi.nlm.nih.gov/pubmed/17273930 PMid:17273930. http://dx.doi.org/10.1007/s10926007-9070-7

Troup, J. D. G. (1978). Driver's back pain and its prevention: a review of the postural, vibratory and muscular factors, together with the problem of transmitted road-shock. Applied Ergonomics, 9(4):207-214. http://dx.doi. org/10.1016/0003-6870(78)90081-9

Tse, J. L. M., Flin, R., \& Mearns, K. (2006). Bus driver well-being review: 50 years of research. Transportation Research Part F: Traffic Psychology and Behaviour, 9(2), 89-114. Retrieved from http://linkinghub.elsevier.com/retrieve/ pii/S1369847805000872 http://dx.doi.org/10.1016/j. trf.2005.10.002

You, H., Bucciaglia, J., Lowe, B., Gilmore, B. J., \& Freivalds, A. (1997). An ergonomic design process for a US transit bus operator workstation. Heavy Vehicle Systems, 4(2), 91107.

Zarifian, P. (2001). Valor de serviço e estratégia de serviço. In M. S. Salerno (Ed.), Relação de serviço, produção e avaliação (pp. 71-96). São Paulo: SENAC. 